\title{
A new benzoxepin metabolite isolated from endophytic fungus Phomopsis sp.
}

\author{
Yoshihito Shiono $^{1}$, Ayumi Nitto ${ }^{1}$, Keiko Shimanuki ${ }^{1}$, Takuya Koseki ${ }^{1}$, Tetsuya Murayama ${ }^{1}$, Tokichi Miyakawa ${ }^{2}$, \\ Jun Yoshida ${ }^{3}$ and Ken-ichi Kimura ${ }^{3}$
}

The Journal of Antibiotics (2009) 62, 533-535; doi:10.1038/ja.2009.65; published online 17 July 2009

Keywords: benzoxepin; benzophomopsin A; $\mathrm{Ca}^{2+}$-signaling; Phomopsis sp.

Endophytes live symptomlessly and intracellularly inside host plants. The interaction of endophytes with host plants has, in particular, received considerable attention. Studies carried out in the last two decades have shown that endophytes are rich sources of structurally diverse natural products with interesting biological activities. ${ }^{1}$ These studies emphasize that chemical compounds help control the equilibrium between the endophytes and the host plants.

In our previous research on novel bioactive compounds isolated from endophytic fungi, we reported eremoxylarins A and B isolated from endophytic fungus xylariaceous YUA-026 as novel calcineurin inhibitors. These compounds were obtained as potential inhibitors of $\mathrm{Ca}^{2+}$-signaling by the use of a yeast-based screening system for the activity that restores the growth of a $\mathrm{Ca}^{2+}$-sensitive, drug-sensitive strain of Saccharomyces cerevisiae $(z d s 1 \Delta \operatorname{erg} 3 \Delta p d r 1 \Delta p d r 3 \Delta)$ on solid medium containing $\mathrm{CaCl}_{2} \cdot{ }^{2,3}$ Among the microbial compounds similarly screened, we found that benzophomopsin A (1) inhibited the $\mathrm{Ca}^{2+}$-signal transduction more strongly than did a known compound, xylarinol A (2) (Figure 1). Herein, we report the isolation and structure elucidation of a new benzoxepin derivative $\mathbf{1}$ together with 2 and their effects on $\mathrm{Ca}^{2+}$-signal transduction.

The producing strain, Phomopsis sp. KS-37-2, was isolated from the stem of a cherry tree in Yamagata, Japan.

Phomopsis sp. KS-37-2 was cultivated on sterilized, unpolished rice $(20 \mathrm{~g} /$ Petri dish $\times 50)$ at $25^{\circ} \mathrm{C}$ for 3 weeks. The moldy, unpolished rice was extracted with $\mathrm{MeOH}$, and the $\mathrm{MeOH}$ extract was concentrated. The resulting aqueous concentrate was extracted with $n$-hexane at first, and the water layer was subsequently partitioned with EtOAc. The purification of the EtOAc layer was guided by the intense blue characteristic coloration with vanillin-sulfuric acid solution on TLC plates. The EtOAc residue was purified on a silica gel column using a stepwise gradient of $n$-hexane-EtOAc (100:0-0:100). The 50-60\% EtOAc fractions $(85.0 \mathrm{mg})$ were combined and further purified by octa decyl silyl (ODS, Fuji Silysia Chemical Ltd., Aichi, Japan) column chromatography using $80 \%$ aqueous $\mathrm{MeOH}$ as the eluent to afford fractions $1-15(100 \mathrm{ml}$ each). Fraction $5(35.0 \mathrm{mg})$ was rechromatographed on a silica gel column using $\mathrm{CHCl}_{3}-\mathrm{MeOH}(80: 20)$ as the eluent to yield benzophomopsin $\mathrm{A}(1,5.5 \mathrm{mg})$ and xylarinol A $(2,11.0 \mathrm{mg})$.

The metabolite xylarinol A (2) was isolated as a white powder. Xylarinol A has recently been isolated from the fruiting bodies of Xylaria polymorpha as a radical scavenger. ${ }^{4} \mathrm{~A}$ comparison of our spectroscopic data with the literature values confirmed that 2 was xylarinol A.

The molecular formula of $\mathbf{1}$ was $\mathrm{C}_{12} \mathrm{H}_{12} \mathrm{O}_{3}$, which required seven degrees of unsaturation, as revealed by HR-FAB-MS. The IR spectrum of 1 showed absorption bands at 3384, 1584 and $1465 \mathrm{~cm}^{-1}$, which are characteristic of the hydroxyl and aromatic groups. The formation of a monomethoxyl derivative (1a) $\left[\mathrm{C}_{13} \mathrm{H}_{14} \mathrm{O}_{3}\right.$ (FAB-MS: $m / z 241$ $\left.\left.[\mathrm{M}+\mathrm{Na}]^{+}\right) ; \delta_{\mathrm{H}} 3.83(3 \mathrm{H}, \mathrm{s}, \mathrm{OMe})\right]$ after treating 1 with trimethylsilyldiazomethane confirmed the presence of a phenolic hydroxyl group. The UV spectrum of 1 revealed the presence of aromatic rings. The ${ }^{13} \mathrm{C}$ NMR and DEPT spectra of 1 showed peaks corresponding to five $\mathrm{sp}^{2}$ methine $(\delta 103.5,114.8,123.0,128.0,131.3)$, three $\mathrm{sp}^{2}$ quaternary carbons $(\delta 126.6,136.9,152.3)$, one $\mathrm{sp}^{3}$ quaternary carbon $(\delta 104.1)$, one $\mathrm{sp}^{3}$ methylene $(\delta 56.8)$, one $\mathrm{sp}^{3}$ methine $(\delta 66.9)$ and one methyl group $(\delta 16.0)$. The seven unsaturation equivalents implied by the molecular formula indicated that $\mathbf{1}$ has three rings.

The ${ }^{1} \mathrm{H}$-NMR spectrum showed signals attributable to a vicinal $\mathrm{sp}^{2}$ spin network [ $\delta 6.82(1 \mathrm{H}, \mathrm{d}, J=7.6 \mathrm{~Hz}), 6.89(1 \mathrm{H}, \mathrm{d}, J=7.6 \mathrm{~Hz}), 7.09$ $(1 \mathrm{H}, \mathrm{t}, J=7.6 \mathrm{~Hz})]$ and two protons of a cis double bond $[\delta 5.95$ $(1 \mathrm{H}, \mathrm{d}, J=12.7 \mathrm{~Hz})$ and $6.82(1 \mathrm{H}, \mathrm{d}, J=12.7 \mathrm{~Hz})]$. In addition, the ${ }^{1} \mathrm{H}$ NMR spectrum revealed signals that were due to an isolated oxymethylene $[\delta 4.63(1 \mathrm{H}, \mathrm{d}, J=13.9 \mathrm{~Hz}), 5.12(1 \mathrm{H}, \mathrm{d}, J=13.9 \mathrm{~Hz})]$, a doublet methyl group $[\delta 1.05(3 \mathrm{H}, \mathrm{d}, J=6.5 \mathrm{~Hz})]$ and an oxymethine

${ }^{1}$ Department of Bioresource Engineering, Faculty of Agriculture, Yamagata University, Tsuruoka, Yamagata, Japan; ${ }^{2}$ Department of Molecular Biotechnology, Graduate School of Advanced Sciences of Matter, Hiroshima University, Higashi-Hiroshima, Japan and ${ }^{3}$ Laboratory of Chemical Biology, Department of Biological Chemistry and Food Science, The United Graduate School of Agricultural Sciences, Iwate University, Morioka, Iwate, Japan

Correspondence: Dr Y Shiono, Department of Bioresource Engineering, Faculty of Agriculture, Yamagata University, Tsuruoka, Yamagata 997-8555, Japan.

E-mail: yshiono@tds1.tr.yamagata-u.ac.jp

Received 23 April 2009; revised 25 June 2009; accepted 29 June 2009; published online 17 July 2009 
<smiles>Cc1c(O)cccc1C=C[C@H]1OC1C</smiles>

$1: \mathrm{R}=\mathrm{H}$ 1a: $\mathrm{R}=\mathrm{OCH}_{3}$

Figure 1 Structures of compounds $\mathbf{1}$ and $\mathbf{2}$.

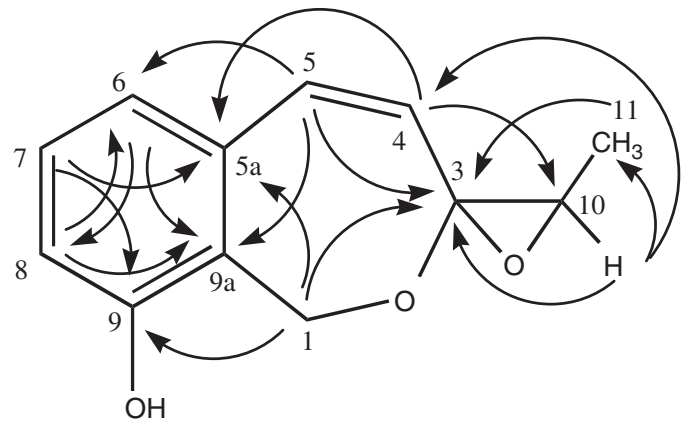

Figure 2 Important HMBC correlations for 1.

group $[\delta 4.15(1 \mathrm{H}, \mathrm{q}, J=6.5 \mathrm{~Hz})]$. For the connectivity of partial structures, we conducted heteronuclear multiple bond correlation (HMBC) experiments (Figure 2 and Table 1). The aromatic moiety in 1 was confirmed on the basis of HMBC correlations from H-6 and $\mathrm{H}-8$ to C-9a and from $\mathrm{H}-7$ to C-5a and C-9. HMBC correlations from $\mathrm{H}-1$ to C-3, C-5a and C-9, from H-4 to C-10, and from H-5 to C-3, C- 6 and C-9a were also observed. These results indicated the presence of a 1,3-dihydro-benzo[c]oxepine moiety in $\mathbf{1}$. The presence of an epoxy group at C-3 and C-10 was confirmed from the molecular formula, the chemical shifts of the ${ }^{1} \mathrm{H}$ and ${ }^{13} \mathrm{C}$ NMR signals at these positions, and the large ${ }^{1} J_{\mathrm{CH}}$ values for $\mathrm{C}-10\left(J_{\mathrm{C}-10, \mathrm{H}-10=153 \mathrm{~Hz}){ }^{5}}\right.$ The residual $\mathrm{OH}$ group was hence thought to be a phenolic $\mathrm{OH}$ located at C-9. The relative stereochemistry of 1 was deduced from NOE experiments. An NOE was observed between H-4 and Me-11. From this result, the relative configuration at the position of C-10 was determined, as shown in Figure 1.

Benzophomopsin A (1), which possesses benzo-fused oxacycloalkenes moiety, was closely related to heptacyclosordariolone and cladoacetal A that were isolated earlier from cultures of Sordaria macrospora and Cladosporium sp., respectively. ${ }^{6,7}$

Intracellular $\mathrm{Ca}^{2+}$ is thought to have an important function in various biological signaling processes. $\mathrm{Ca}^{2+}$ has also been found to affect the progression of the $\mathrm{G} 2 / \mathrm{M}$ cell cycle multilaterally in the yeast S. cerevisiae. ${ }^{8}$ The mutant yeast strain $(z d s 1 \Delta \operatorname{erg} 3 \Delta p d r 1 \Delta p d r 3 \Delta)$ used in this study is unable to grow at high $\mathrm{CaCl}_{2}$ concentrations because of the hyperactivation of the $\mathrm{Ca}^{2+}$-signal pathway. Two parallel pathways of $\mathrm{Ca}^{2+}$-signaling, calcineurin and Mpk1 MAP kinase cascade, coordinately activate Swe1 in response to $\mathrm{CaCl}_{2}$. Swe1, in turn, activates the inhibitory phosphorylation of the $\mathrm{Cdc} 28$ cyclin-dependent protein kinase in the G2 phase, resulting in cell cycle arrest in G2/M. ${ }^{9}$ Thus, the calcineurin inhibitor, FK506, and the heat-shock protein 90 inhibitor, radicicol, by inhibiting the $\mathrm{Ca}^{2+}$-induced Swel activation, promote the growth of the $z d s 1 \Delta$ strain yeast on $\mathrm{Ca}^{2+}$-agar plate. ${ }^{9,10}$ The growth-promoting activities of compounds $\mathbf{1}$ and $\mathbf{2}$ were
Table $1{ }^{1} \mathrm{H}$ and ${ }^{13} \mathrm{C}$-NMR data of 1

\begin{tabular}{lccc}
\hline No & $\delta_{C}$ & $\delta_{H}$ & $H M B C$ \\
\hline 1 & $56.8 \mathrm{t}$ & $4.63(1 \mathrm{H}, \mathrm{d}, 13.9)$ & $3,5 \mathrm{a}, 9$ \\
& & $5.12(1 \mathrm{H}, \mathrm{d}, 13.9)$ & $3,5 \mathrm{a}, 9$ \\
3 & $104.1 \mathrm{~s}$ & & \\
4 & $103.5 \mathrm{~d}$ & $5.95(1 \mathrm{H}, \mathrm{d}, 12.7)$ & $5 \mathrm{a}, 10$ \\
5 & $131.3 \mathrm{~d}$ & $6.82(1 \mathrm{H}, \mathrm{d}, 12.7)$ & $3,6,9 \mathrm{a}$ \\
$5 \mathrm{a}$ & $136.9 \mathrm{~s}$ & & \\
6 & $123.0 \mathrm{~d}$ & $6.89(1 \mathrm{H}, \mathrm{d}, 7.6)$ & $8,9 \mathrm{a}$ \\
7 & $128.0 \mathrm{~d}$ & $7.09(1 \mathrm{H}, \mathrm{t}, 7.6)$ & 5,9 \\
8 & $114.8 \mathrm{~d}$ & $6.82(1 \mathrm{H}, \mathrm{d}, 7.6)$ & $6,9 a$ \\
9 & $152.3 \mathrm{~s}$ & & $3,4,11$ \\
$9 \mathrm{a}$ & $126.6 \mathrm{~s}$ & & 3,10 \\
10 & $66.9 \mathrm{~d}$ & $4.15(1 \mathrm{H}, \mathrm{q}, 6.5)$ & \\
11 & $16.0 \mathrm{q}$ & $1.05(3 \mathrm{H}, \mathrm{d}, 6.5)$ & \\
\hline
\end{tabular}

${ }^{13} \mathrm{C}-(100 \mathrm{MHz})$ and ${ }^{1} \mathrm{H}-(400 \mathrm{MHz})$ NMR spectra were taken on JEOL NMR system EX-400 in $\mathrm{CDCl}_{3}$, the solvent peak were used as internal standard $\left(\delta_{\mathrm{C}} 77.0, \delta_{\mathrm{H}} 7.26\right)$, and values in parentheses were coupling constants in $\mathrm{Hz}$.
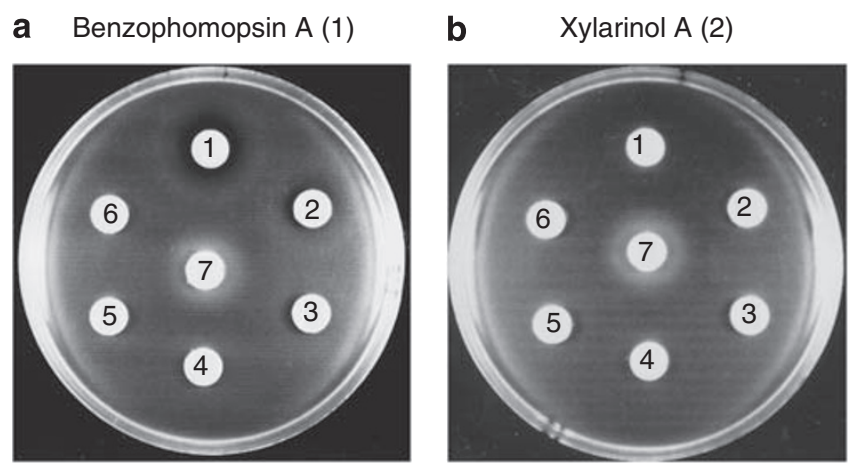

Figure 3 Restored growth activity of $\mathbf{1}$ (a) and $\mathbf{2}$ (b) against the mutant strain of Saccharomyces cerevisiae ( $z d s 1 \Delta$ erg $3 \Delta$ pdr $1 \Delta$ pdr $3 \Delta$ ) with $0.3 \mathrm{~m}$ $\mathrm{CaCl}_{2}$. Assays were carried out as described earlier. ${ }^{3} 1: 10 \mu \mathrm{g}$ per disc, 2 : $5 \mu \mathrm{g}$ per disc, 3: $2.5 \mu \mathrm{g}$ per disc, 4: $1.25 \mu \mathrm{g}$ per disc, 5: $0.625 \mu \mathrm{g}$ per disc, 6: $0.31 \mu \mathrm{g}$ per disc, 7: $0.02 \mu \mathrm{g}$ per disc (FK506).

determined semi-quantitatively by similar procedures used for the screening assay. ${ }^{3}$ Paper discs containing different amounts of compounds 1 and $\mathbf{2}$ were placed on a YPD agar plate containing $\mathrm{CaCl}_{2}$ and the cell-growth zones formed around the discs were observed after 3 days of incubation at $28^{\circ} \mathrm{C}$. Compound 1 gave rise to a growth zone at $1.25 \mu \mathrm{g}$ per disc and it restored the growth inhibition caused by a high $\mathrm{Ca}^{2+}$ dose dependently (Figure 3 ). In contrast, the activity of compound 2 was much weaker, giving rise to only a faint growth zone at $10 \mu \mathrm{g}$ per disc of this compound. The activity of 1 observed by this assay was apparently similar to those observed with eremoxylarins A and $\mathrm{B}$, which were found to inhibit calcineurin. ${ }^{3}$ However, 1 did not inhibit calcineurin even at $100 \mu \mathrm{M}$ (data not shown). Though YCM1008A is already known as a $\mathrm{Ca}^{2+}$-signaling inhibitor from Fusarium sp., ${ }^{11} \mathbf{1}$ has different structures and producing strain from it. Thus, further studies are required for an in-depth understanding of the inhibitory activity of 1 .

\section{PHYSICO-CHEMICAL PROPERTIES}

1: White powder amorphous; $[\alpha]_{\mathrm{D}}{ }^{20}-46^{\circ}(c 0.11, \mathrm{MeOH}), \mathrm{UV} \lambda_{\max }$ $\mathrm{MeOH} \mathrm{nm}(\varepsilon) 253$ (27,000), 261 (sh, 22,000), IR (KBr) $v_{\max } \mathrm{cm}^{-1}$ $3384,1584,1465,1014$, FAB-MS: $m / z 205(\mathrm{M}+\mathrm{H})^{+}$, HR-FAB-MS $m / z$ 205.0872 (calcd for $\mathrm{C}_{12} \mathrm{H}_{12} \mathrm{O}_{3}+\mathrm{H}, 205.0865$ ), for ${ }^{1} \mathrm{H}$ and ${ }^{13} \mathrm{C}$ NMR see Table 1. 
1a: Yellow oil, ${ }^{1} \mathrm{H}-\mathrm{NMR}\left(400 \mathrm{MHz}, \mathrm{CDCl}_{3}\right) \delta 1.05(1 \mathrm{H}, \mathrm{d}, J=6.5 \mathrm{~Hz}$, 11-Me), 3.83 (3H, s, 9-OMe), $4.58(1 \mathrm{H}, \mathrm{d}, J=13.8 \mathrm{~Hz}, 1-\mathrm{H}), 5.18(1 \mathrm{H}$, d, $J=13.8 \mathrm{~Hz}, 1-\mathrm{H}), 5.97(1 \mathrm{H}, \mathrm{d}, J=12.5 \mathrm{~Hz}, 4-\mathrm{H}), 6.76(1 \mathrm{H}, \mathrm{d}$, $J=12.5 \mathrm{~Hz}, 5-\mathrm{H}), 6.82(1 \mathrm{H}, \mathrm{d}, J=7.6 \mathrm{~Hz}, 8-\mathrm{H}) .6 .94(1 \mathrm{H}, \mathrm{d}, J=7.6 \mathrm{~Hz}$, 6-H), $7.24(1 \mathrm{H}, \mathrm{t}, J=7.6 \mathrm{~Hz}, 7-\mathrm{H})$. FAB-MS: $m / z 241(\mathrm{M}+\mathrm{Na})^{+}$.

\section{ACKNOWLEDGEMENTS}

We thank Ms. Teiko Yamada of the Faculty of Agriculture at Tohoku University for HR-MS measurements.

1 Gunatilaka, A. A. L. Natural products from plant-associated microorganisms: distribution, structural diversity, bioactivity, and implications of their occurrence. J. Nat. Prod. 69, 509-526 (2006).

2 Shiono, Y. \& Murayama, T. New eremophilane-type sesquiterpenoids, eremoxylarins A and B from xylariaceous endophytic fungus YUA-026. Z. Naturforsch. 60b, 885-890 (2005).
3 Ogasawara, Y., Yoshida, J., Shiono, Y., Miyakawa,, T. \& Kimura, K. New eremophilane sesquiterpenoid compounds, eremoxylarins $A$ and $B$ directly inhibit calcineurin in a manner independent of immunophilin. J. Antibiot. 61, 496-502 (2008).

4 Lee, I. et al. Xylarinols $A$ and $B$, two new 2-benzoxepin derivatives from the fruiting bodies of Xylaria polymorpha. J. Antibiot. 62, 163-165 (2009).

5 Someno, T. et al. ICM0301s, new angiogenesis inhibitors from Aspergillus sp. F-1491. II. Physico-chemical properties and structure elucidation. J Antibiot. 57, 104-109 (2004).

6 Bouillant, M. L., Bernillon, J., Favre-Bonvin, J. \& Salin, N. New hexaketides related to sordariol in Sordaria macrospora. Z. Naturforsch. 44c, 719-723 (1989).

7 Höller, U., Gloer, J. B. \& Wicklow, D. T. Biologically active polyketide metabolites from an undetermined fungicolous hyphomycete resembling Cladosporium. J. Nat. Prod. 65, 876-882 (2002).

8 Mizunuma, M., Hirata, D., Miyahara, K., Tsuchiya, E. \& Miyakawa, T. Role of calcineurin and Mpk1 in regulating the onset of mitosis in budding yeast. Nature 392, 303-306 (1998).

9 Shitamukai, A., Mizunuma, M., Hirata, D., Takahashi, H. \& Miyakawa, T. A positive

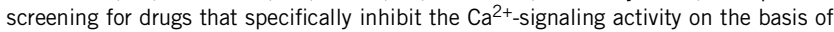
the growth promoting effect on a yeast mutant with a peculiar phenotype. Biosci. Biotechnol. Biochem. 64, 1942-1946 (2000).

10 Chanklan, R. et al. Inhibition of $\mathrm{Ca}^{2+}$-signal-dependent growth regulation by radicicol in budding yeast. Biosci. Biotechnol. Biochem. 72, 132-138 (2008).

11 Koizumi, F. et al. YCM1008A, a novel $\mathrm{Ca}^{2+}$-signaling inhibitor, produced by Fusarium sp. YCM1008. J. Antibiot. 60, 455-458 (2007). 